Some programmes, such as the GAVI Alliance - formerly the Global Alliance for Vaccines and Immunisation — have seen pledges increase this year (see go.nature.com/qlldf4), and donors must follow through with the cash. Others have not been so lucky. Donations to the Global Fund to Fight AIDS, Tuberculosis and Malaria, for example, last year fell far short of its funding target (see Nature 467, 767; 2010). And the comprehensive Global Funding of Innovation for Neglected Diseases (G-Finder) report, due next month, is expected to say that most donors slashed funding for neglected-disease research and development last year - causing an overall fall of more than $\$ 100$ million, or more than $5 \%$. The risk is that the financial crisis could roll back the huge progress that has been made in both funding and outcomes for global health and research since neglected diseases returned to the international agenda in the mid-1990s - and also stymie a recent resurgence of interest in agricultural research and development (R\&D) for developing nations.

To combat this threat, Gates rightly emphasized the urgent need for new funding mechanisms to boost development and make it less vulnerable to financial turmoil. And he made a compelling case for measures that, between them, could potentially raise more than $\$ 100$ billion a year. Gates also put his finger on a key point: cash flow between rich and poor countries is not a one-way street of aid from donors to recipients. Many poorer nations have substantial natural resources, the revenues from which exceed that of aid. Yet countries are sometimes given raw deals by foreign companies exploiting those resources, and revenues can also end up in the bank accounts of corrupt public officials. The result is a haemorrhaging of financial resources, some of which could otherwise be spent on building labs, hospitals and sanitation systems, training researchers and doctors, or buying bed nets and drugs.

To tackle this, Gates called on the G20 countries to embrace the Extractive Industries Transparency Initiative (EITI), a World Bankbacked scheme, launched in 2002, to oblige companies and countries to make public the terms of oil, gas and mineral deals in order to better

monitor both whether the deals are fair and where that money goes. The sums involved are potential game changers that could also transform neglected diseases and agricultural R\&D. Gates points out that, at peak production, Uganda's oil reserves are estimated to generate $\$ 2$ billion annually, which is almost as much as the country's entire national budget of $\$ 3$ billion. However, the confidentiality of the terms of deals with firms makes it impossible to track either whether countries are

"Cashflow poor countries is not a one-way street." between rich and getting good deals, or where all the cash goes.

The EITI is gaining traction, and teeth, with US President Barack Obama announcing in September that the United States would adopt legislation to make it EITI compliant, and the European Union is considering following suit. But Gates is right to call on all G20 countries to endorse the EITI, and to force companies listed on their stock exchanges to disclose the royalties they pay to governments - and for that measure to be extended to resources such as land and timber.

Gates also called for a share of sovereign wealth funds to be invested in infrastructure, and lent his support to proposals for a small tax on tobacco and financial transactions, and a carbon tax on aviation and shipping fuel, which together could raise at least tens of billions of dollars. Financial-transaction taxes already exist in several countries, and, as Gates said, "are clearly technically feasible". Likewise, UNITAID, an international organization that helps to accelerate development and scale-up of access to treatments for HIV and AIDS, malaria and tuberculosis, is largely financed by an airline tax paid by its member states.

Gates deserves great credit for highlighting these issues and helping to keep them on the international agenda. Research leaders and politicians must press for them to remain there, and for action to follow. It would be a fitting result if the man whose operating systems forced the world to learn the keyboard sequence CTRL-ALT-DEL can spark a much-needed reboot of funding of research for development.

\section{Hubble cleared}

\section{A painstaking study absolves US astronomer Edwin Hubble of censoring a Belgian rival.}

\footnotetext{
$\mathrm{E}$
} dwin Hubble is that relatively rare thing among dead astronomers - a global household name. He owes his status mainly to the NASA space telescope named in his honour. So when researchers suggested this year that Hubble might have censored the work of a rival to secure credit for the groundbreaking discovery that the Universe is expanding, they triggered a fuss that was far removed from the usual arcane wrangling over historical research priority.

In an admirably thorough Comment on page 171, Mario Livio, an astronomer at the Space Telescope Science Institute in Baltimore, Maryland, clears Hubble of wrongdoing. As a result, NASA and a generation of researchers whose careers are closely tied to the Hubble brand can look skywards with some relief.

The charges against Hubble certainly warranted examination. In 1927, the Belgian astronomer Georges Lemaitre published a Frenchlanguage paper in the Annales de la Société Scientifique de Bruxelles that laid out the essentials of a picture of galaxies expanding away from one another, and derived an expansion parameter on the basis of then-recent observations. In 1929, Hubble independently put forward and confirmed the same idea, and the parameter later became known as the Hubble constant. In 1931, Lemaître's paper was translated into English and published in the Monthly Notices of the Royal Astronomical Society, but most English speakers probably learned of Hubble's contribution before they learned of Lemaître's.

Suspicions of foul play emerged earlier this year, when amateur historians noticed that the derivation of the expansion constant is missing from the English translation of Lemaitre's work. Knowing that Hubble was concerned that he, and the Mount Wilson Observatory in Pasadena, California, at which he made his observations, should get ample credit for confirming the expansion of the Universe, it was tempting to speculate that he had a hand in the editing of the Belgian's paper. But motive alone doesn't build a case, and professional historians, who had known of the irregularity for years, remained sceptical.

Livio's research suggests that they were right to hesitate. After reviewing hundreds of documents in the archives of the Royal Astronomical Society in London, Livio found a copy of a 1931 letter by Lemaitre in which he said that in translating his paper, he had deleted discussion of the velocities of galaxies because it was "of no actual interest". Why exactly Lemaître thought this is unclear, but it seems that he was not very concerned about getting the credit for his work in the way that modern followers have assumed; instead, he may have worried more about seeming out of date, given that the data on which the expansion constant was based had been improved since 1927.

The idea that the accuracy of papers and their relevance to colleagues ought to be more important than ensuring priority at every step may seem fantastic in today's cut-throat world of science. And perhaps it was then, too. Perhaps Lemaitre was simply so flattered to be invited to translate his paper that, aware of Hubble's importance among English-speakers and fearful of repercussions, or eager to join the Royal Astronomical Society, he self-censored. The case against Hubble is closed, but there may still be a story for motivated historians to look into.

Space agencies should also take note. Whether or not Hubble deliberately censored Lemaitre, the fact is that in the $\rightarrow$ NATURE.COM To comment online, click on Editorials at: go.nature.com/xhunqv English-speaking world, Lemaitre has lost - to Hubble - priority for his contributions. The Belgian's name is a worthy candidate for the title of a future space mission.. 